\title{
miRNA-125b regulates apoptosis of human non-small cell lung cancer via the PI3K/Akt/GSK3ß signaling pathway
}

\author{
YINGYI WANG ${ }^{1-5^{*}}$, MING ZHAO $^{2 *}$, JIEYING LIU $^{1-5}$, ZHAO SUN $^{1-5}$, JIANJIAO NI $^{3}$ and HONGSHENG LIU ${ }^{4,5}$ \\ ${ }^{1}$ Oncology Department of Peking Union Medical College Hospital, Chinese Academy of Medical Sciences, \\ Dongcheng, Beijing 100730; ${ }^{2}$ Thoracic Surgery Department of China PLA General Hospital, Haidian, Beijing 100853; \\ ${ }^{3}$ Peking Union Medical College, Chinese Academy of Medical Sciences, Dongcheng, Beijing 100730; \\ ${ }^{4}$ Department of Thoracic Surgery, Peking Union Medical College Hospital, Dongcheng, Beijing 100730; \\ ${ }^{5}$ Graduate School of Peking Union Medical College, Chinese Academy of Medical Sciences, \\ Dongcheng, Beijing 100730, P.R. China
}

Received August 22, 2016; Accepted June 21, 2017

DOI: 10.3892/or.2017.5808

\begin{abstract}
The present investigation demonstrated that regulation of microRNA (miR)-125b affected the apoptosis of human non-small cell lung cancer (NSCLC) through targeting of the $\mathrm{PI} 3 \mathrm{~K} / \mathrm{Akt}$ and $\mathrm{Wnt} / \mathrm{\beta}$-catenin signaling pathways. The expression of miR-125b was assessed in patients with NSCLC, which demonstrated that miR-125b expression in NSCLC tissue was higher than that in para-carcinoma tissue. Furthermore, survival analysis of patients with NSCLC over 3 years indicated that the overall survival (OS) and disease-free survival (DFS) rates of patients with low miR-125b expression were higher than those of patients with high miR-125b expression. Proliferation and apoptosis assays were subsequently conducted in the human NSCLC cell line A549 using MTT assay and Annexin V-FITC/PI kits, respectively. Caspase-3 activity ELISA and western blot analysis were also used to assess caspase- 3 activity and the protein expression of Bax, Akt, phosphorylated (p)-Akt, p-GSK3 $\beta$, Wnt and $\beta$-catenin. It was observed that downregulation of miR-125b inhibited the proliferation and induced the apoptosis of A549 cells. Downregulation of miR-125b also suppressed the protein expression of p-Akt, Wnt and $\beta$-catenin, and increased caspase-3 activity and Bax protein expression in A549 cells. In addition, downregulation of miR-125b combined with the PI3K inhibitor LY294002 enhanced cell growth inhibition, suppression of $\mathrm{p}$-GSK3 $\beta$, Wnt and $\beta$-catenin protein expression and promotion of caspase- 3 activity in A549 cells. These
\end{abstract}

Correspondence to: Dr Hongsheng Liu, Department of Thoracic Surgery, Peking Union Medical College Hospital, 1 Shuaifuyuan, Dongcheng, Beijing 100730, P.R. China

E-mail: muhechuojiao30@126.com

${ }^{*}$ Contributed equally

Key words: miR-125b, PI3K/Akt, non-small cell lung cancer, Wnt, $\beta$-catenin results revealed that the downregulation of miR-125b regulates apoptosis in human NSCLC through the suppression of the $\mathrm{PI} 3 \mathrm{~K} / \mathrm{Akt} / \mathrm{GSK} 3 \beta$ and Wnt/ $\beta$-catenin signaling pathways.

\section{Introduction}

Primary bronchogenic carcinoma (also known as lung cancer) refers to malignant tumors that originate in the bronchus, mucous gland, bronchiolar epithelium or pulmonary alveolar epithelium (1). Lung cancer is among the most common malignant tumors in China. Its rate of morbidity has markedly increased over recent years, and is now ranked highest in a number of cities. Furthermore, its yearly incidence now exceeds 500,000 cases (2), with a male:female ratio of $~ 7-7: 1$. However, as the biological behaviors of tumors differ, lung cancer is generally divided into small cell lung cancer (SCLC) and non-small cell lung cancer (NSCLC) for convenient clinical treatment (3). The latter includes all epithelium-derived lung cancers excluding SCLCs. At present, the first-choice therapeutic method for early-stage lung cancer is surgical treatment (4), while the main treatment methods for locally advanced lung cancer include radiotherapy, chemotherapy, surgery and comprehensive treatment involving a combination of these methods (3).

In glycogen synthase kinase (GSK)-3 $\beta$, phosphorylation of the ninth serine inactivates the kinase, which can prevent the Wnt signal transduction pathway and cause degradation of the protein, inhibiting apoptosis (5). Meanwhile, phospho(p)GSK-3 prevents GSK-3 $\beta$ from interacting with $\beta$-catenin and cyclin D1, enabling the overexpression of $\beta$-catenin and cyclin D1, which favors the binding of cyclin D1 to CDK $4 / 6$ to form a complex that promotes the G1/S phase transition in cells (6). The cells can then enter into the $S$ phase of the cell cycle, and may ultimately overproliferate and malignantly transform (6).

Research into the PI3K/Akt signaling pathways now spans $>10$ years. After PI3K phosphorylation, the second messenger phosphatidylinositol (PIP3) is generated on the plasmalemma (7). PIP3 can then bind to the N-terminal of Akt, which contains a PH structural domain for such binding. 
This activates Akt and transfers it to the cytosolic side of the plasmalemma (8), where Akt itself activates or suppresses downstream target proteins through phosphorylation, which ultimately stimulates the proliferation, differentiation, apoptosis and migration of target cells (9). As major kinases of inositol and phosphatidylinositol, PI3K family members are considered to be primary cancer genes, and are composed of the regulatory subunit $\mathrm{p} 85$ and catalytic subunit $\mathrm{p} 110$. The catalytic subunit is responsible for catalyzing phosphorylation of the third hydroxyl of the inositol ring (10). Akt is a serine/threonine protein kinase with a molecular weight of $57 \mathrm{ku}$, and is the mammalian congener of the viral protooncogene Akt (11). Following activation of the PI3K/Akt signaling pathway, activated Akt exerts its effects through the activation of multiple downstream effector molecules, including Bad, caspase-9, FKHR1 and NF- $\kappa \mathrm{B}$, enabling it to participate in the suppression of apoptosis and regulation of the cell cycle (12). At present, a relatively well-established effect of Akt is its upregulation of gene expression through increased transcription of c-Myc. c-Myc is a type of cell cycle-associated factor that enables cells to exit the G0 phase and undergo proliferation (11), and may also promote tumor angiogenesis. Similarly, Akt can activate nitric oxide synthase, stimulate the growth and proliferation of endothelial cells and increase vascular permeability (13). Furthermore, after hemangiectasis, Akt can promote neovascularization, aiding with the provision of sufficient nutrition for tumor cells, and can also promote cell invasion and metastasis.

Previous evidence revealed that microRNAs (miRs) serve important roles in the occurrence and development of human tumors (14). Recently, it has been demonstrated that miR-125b and its target gene play a critical role in the invasion and metastasis of multiple tumor types (15). For example, miR-125b can directly regulate c-Jun protein expression and directly suppress the metastasis of melanoma cells on a transcriptional and translational level (16). It has also been reported that miR-125b can act as a tumor-inhibitory factor that targets the PI3K/Akt signaling pathway, and prevents the invasion and metastasis of cervical cancer cells (16). Therefore, the aim of the present study was to evaluate the effects of miR-125b regulation on the apoptosis of human NSCLC cells and the targeting of the $\mathrm{PI} 3 \mathrm{~K} / \mathrm{Akt}$ and $\mathrm{Wnt} / \beta$-catenin signaling pathways in vitro.

\section{Materials and methods}

Patients and specimen selection. Approval for the present study was obtained from the local Ethics Committee along with written informed consent from each patient. From September to December of 2012, human NSCLC specimens from patients $(n=91)$ were obtained from the Department of Oncology of Peking Union Medical College Hospital, Chinese Academy of Medical Sciences. The main characteristics of all human NSCLC specimens from patients are shown in Table I. Every 2 months, a follow-up of NSCLC patients was conducted, over a 3-year period. We analyzed overall survival (OS) and disease-free survival (DFS) in the present study.

Quantative real-time PCR analysis. Total RNA was extracted from NSCLC and para-carcinoma tissues using TRIzol ${ }^{\circledR}$ (Invitrogen, Thermo Fisher Scientific, Inc., Waltham, MA,
Table I. Association between miR-125b expression and clinicopathological features.

\begin{tabular}{|c|c|c|c|c|}
\hline \multirow[b]{2}{*}{ Variables } & \multirow{2}{*}{$\begin{array}{l}\text { No. of } \\
\text { pts. }\end{array}$} & \multicolumn{2}{|c|}{ miR-125b expression } & \multirow[b]{2}{*}{$\mathrm{P}$-value } \\
\hline & & Low $(\%)$ & High $(\%)$ & \\
\hline Sex & & & & 0.437 \\
\hline Male & 79 & $42(53.16)$ & $37(46.84)$ & \\
\hline Female & 12 & $4(33.33)$ & $8(66.67)$ & \\
\hline Age (years) & & & & 0.014 \\
\hline$\leq 60$ & 57 & $21(36.84)$ & $36(63.16)$ & \\
\hline$>60$ & 34 & $18(52.94)$ & $16(47.06)$ & \\
\hline $\begin{array}{l}\text { Pathological } \\
\text { differentiation }\end{array}$ & & & & 0.627 \\
\hline High & 7 & $5(71.43)$ & $2(28.57)$ & \\
\hline Median & 61 & $23(37.70)$ & $38(62.30)$ & \\
\hline Low & 23 & $13(56.52)$ & $10(43.48)$ & \\
\hline Clinical stage & & & & 0.139 \\
\hline I & 7 & $3(42.86)$ & $4(57.14)$ & \\
\hline II & 17 & $6(35.29)$ & $11(64.71)$ & \\
\hline IIIA & 67 & $38(56.71)$ & $29(43.28)$ & \\
\hline Vascular invasion & & & & 0.074 \\
\hline Negative & 84 & $41(48.81)$ & 43 (51.19) & \\
\hline Positive & 7 & $2(28.57)$ & $5(71.43)$ & \\
\hline Pathological type & & & & 0.000 \\
\hline Squamous cancer & 39 & $25(64.10)$ & $14(35.90)$ & \\
\hline Adenocarcinoma & 47 & $15(31.91)$ & $32(68.09)$ & \\
\hline Large cell cancer & 5 & $2(40.00)$ & $3(60.00)$ & \\
\hline
\end{tabular}

pts., patients.

USA). cDNA was synthesized from total RNA (100-200 ng) using M-MLV reverse transcriptase (Promega Corporation, Madison, WI, USA) with random primers (Takara Bio, Inc., Otsu, Japan), according to the manufacturer's protocol. Quantitative real-time PCR analysis was performed using the CFX Connect ${ }^{\mathrm{TM}}$ Real-Time PCR Detection System (Bio-Rad Laboratories, Inc., Hercules, CA, USA) and SYBR ${ }^{\circledR}$-Green PCR Master Mix kit (Applied Biosystems, Thermo Fisher Scientific, Inc.). Quantative real-time PCR analysis was performed with 1 cycle at $95^{\circ} \mathrm{C}$ for $10 \mathrm{~min}$, followed by 40 cycles of $95^{\circ} \mathrm{C}$ for $30 \mathrm{sec}$ and $58^{\circ} \mathrm{C}$ for $60 \mathrm{sec}$.

Cell culture. The human NSCLC A549 cell line was purchased from the Shanghai Cell Bank (Shanghai, China), and maintained in RPMI-1640 medium supplemented with $10 \%$ fetal bovine serum (both from Gibco; Thermo Fisher Scientific Inc.) with $100 \mathrm{U} / \mathrm{ml}$ streptomycin and $100 \mathrm{U} / \mathrm{ml}$ penicillin (both from Thermo Fisher Scientific, Inc.) at $37^{\circ} \mathrm{C}$ in a humidified atmosphere containing $5 \% \mathrm{CO}_{2}$.

Transfection and lentiviral transduction. Anti-miR-125b mimics and negative plasmids were transfected into A549 cells using Lipofectamine 2000 transfection reagent (Thermo Fisher Scientific, Inc.), following the manufacturer's protocol. 


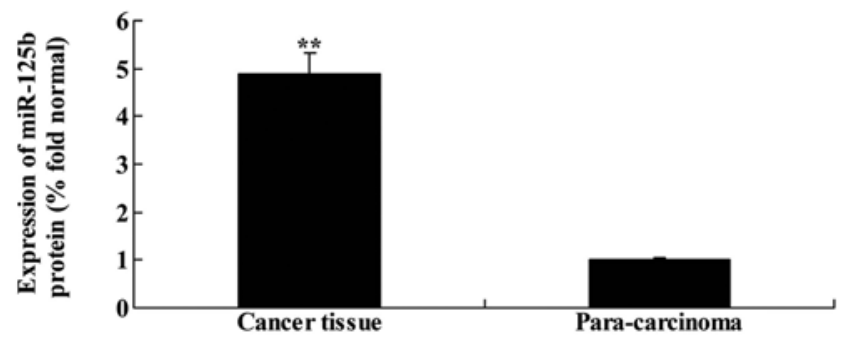

Figure 1. miR-125b expression in human non-small cell lung cancer. Cancer tissue, non-small cell lung cancer tissue; para-carcinoma, para-carcinoma tissue; ${ }^{* *}$ p $<0.01$ compared with para-carcinoma tissue.

After transfection for $24 \mathrm{~h}$, the cells were maintained in new culture medium and used to execute experimental research.

Cell proliferation assay. A549 cells transfected with anti-miR-125b mimics and negative plasmids or treated with LY294002 $(1 \mu \mathrm{M})$ for $48 \mathrm{~h}$ were assayed $96 \mathrm{~h}$ later using an MTT assay kit $(50 \mu \mathrm{g} / \mathrm{ml}$; Sigma-Aldrich, St. Louis, MO, USA) for $4 \mathrm{~h}$. Subsequently, the culture medium was removed and $150 \mu 1$ of dimethyl sulfoxide (DMSO) (Sigma-Aldrich) was added into cells to dissolve. The absorbance was assessed using a Genesys ${ }^{\mathrm{TM}} 15$ ultraviolet spectrophotometer (Thermo Fisher Scientific, Inc.) at $492 \mathrm{~nm}$.

Cell apoptosis assay. A549 cell transfected with anti-miR-125b mimics and negative plasmids or treated with LY294002 $(1 \mu \mathrm{M})$ for $48 \mathrm{~h}$ was assayed $6 \mathrm{~h}$ later using Annexin V-FITC/PI apoptosis assay. Annexin V-FITC (BD Biosciences, San Jose, CA, USA) was added and incubated for $20 \mathrm{~min}$ at room temperature in the dark. Then, PI (BD Biosciences) was also added and incubated for $5 \mathrm{~min}$ at room temperature in the dark. Then, cell apoptosis was examined using a FACScan flow cytometer.

Caspase-3 activity assay. A549 cells transfected with anti-miR-125b mimics and negative plasmids or treated with LY294002 $(1 \mu \mathrm{M})$ for $48 \mathrm{~h}$ were assayed $96 \mathrm{~h}$ later using a caspase- 3 activity ELISA kit for $1 \mathrm{~h}$ at $37^{\circ} \mathrm{C}$. Caspase- 3 activity was assessed using a Genesys ${ }^{\mathrm{TM}} 15$ ultraviolet spectrophotometer (Thermo Fisher Scientific, Inc.) at $405 \mathrm{~nm}$.

Western blot analysis. A549 cells transfected with anti-miR-125b mimics and negative plasmids or treated with LY294002 $(1 \mu \mathrm{M}) 48 \mathrm{~h}$ later. A549 cells were lysed with a hypotonic buffer containing a protease inhibitor cocktail (both from Beyotime Institute of Biotechnology, Shanghai, China). Protein concentration was determined by the BCA method (Beyotime Institute of Biotechnology). Equal protein $(50 \mu \mathrm{g})$ was separated by $10 \%$ SDS-polyacrylamide gel and blotted onto a polyvinylidene difluoride (PVDF) membranes (BD Biosciences). The membranes were incubated with Akt (1:500), phosphorylated (p)-Akt (1:500), p-GSK3 $\beta$ (1:500), Wnt (1:500), $\beta$-catenin (1:300), Bax (1:300) and GAPDH (1:500) (all from Santa Cruz Biotechnology, Inc., Santa Cruz, CA, USA) at $4^{\circ} \mathrm{C}$ overnight. Following washing with PBS with Tween-20 (Sigma-Aldrich) twice, membranes were incubated with horseradish peroxidase-conjugated secondary antibody
IgG (Santa Cruz Biotechnology, Inc.). Subsequently the membranes were revealed with an Amersham ECL Western Blotting Detection kit (EMD Millipore, Billerica, MA, USA).

Statistical analysis. Data are expressed as the mean \pm standard deviation. Comparison between the means of two groups was performed using Student's t-test and one-way analysis of variance followed by post hoc pairwise comparisons using Tukey's test. $\mathrm{p}<0.05$ was considered to indicate a statistically significant difference.

\section{Results}

miR-125b expression in human non-small cell lung cancer. Patients with NSCLC ( $\mathrm{n}=91)$ were recruited from the Oncology Department of the Peking Union Medical College Hospital, Chinese Academy of Medical Sciences, and the expression of miR-125b was assessed in all patients using quantitative PCR. As shown in Fig. 1, the expression of miR-125b in NSCLC tissue was higher than that in para-carcinoma tissue.

Association between miR-125b expression and clinicopathologicalfeatures. To determine the regulatory role of miR-125b in human NSCLC, we examined the association between miR-125b expression and the clinicopathological features of patients. As shown in Table I, differences were observed between miR-125b expression and the pathological type of NSCLC, and between miR-125b expression and the age of patients with NSCLC.

Association between miR-125b expression and $O S$ and DFS rates. A follow-up of NSCLC patients was conducted over a 3-year period, in which the OS and DFS rates of patients were recorded. As shown in Fig. 2A and B, the 3-year OS and DFS rates in patients with low miR-125b expression were higher than those in patients with high miR-125b expression.

Downregulation of miR-125b inhibits the proliferation of A549 cells. To assess the effects of miR-125b on the proliferation of A549 cells, we investigated cell growth with an MTT assay. Firstly, downregulation of miR-125b significantly suppressed the expression of miR-125b in A549 cells when compared with a negative control group (Fig. 3A). Notably, we found that miR$125 \mathrm{~b}$ markedly suppressed A549 cell proliferation at 24 and $48 \mathrm{~h}$ when compared with the negative control group (Fig. 3B).

Downregulation of miR-125b induces apoptosis in A549 cells. To examine whether downregulation of miR-125b induced the apoptosis of A549 cells, as indicated by the aforementioned results, an Annexin V-FITC/PI apoptosis assay was used to analyze changes in the rate of apoptosis. The results revealed that downregulation of miR-125b significantly increased the rate of apoptosis and promoted cell death in A549 cells when compared with the negative control group (Fig. 4).

Downregulation of miR-125b suppresses the protein expression of $p$-Akt, $p$-GSK3 $\beta$, Wht and $\beta$-catenin in A549 cells. We used western blot analysis to detect the protein expression of p-Akt, p-GSK3 $\beta$, Wnt and $\beta$-catenin in A549 cells. The results revealed that the downregulation of $\mathrm{miR}-125 \mathrm{~b}$ significantly 
A

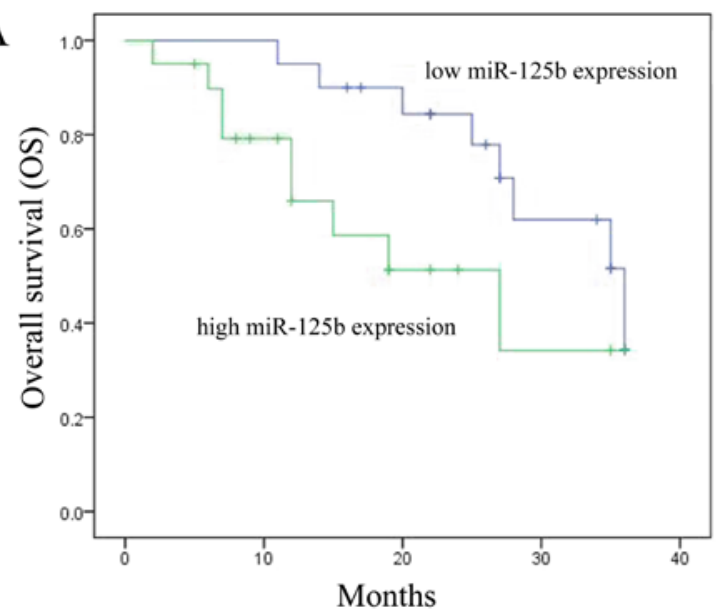

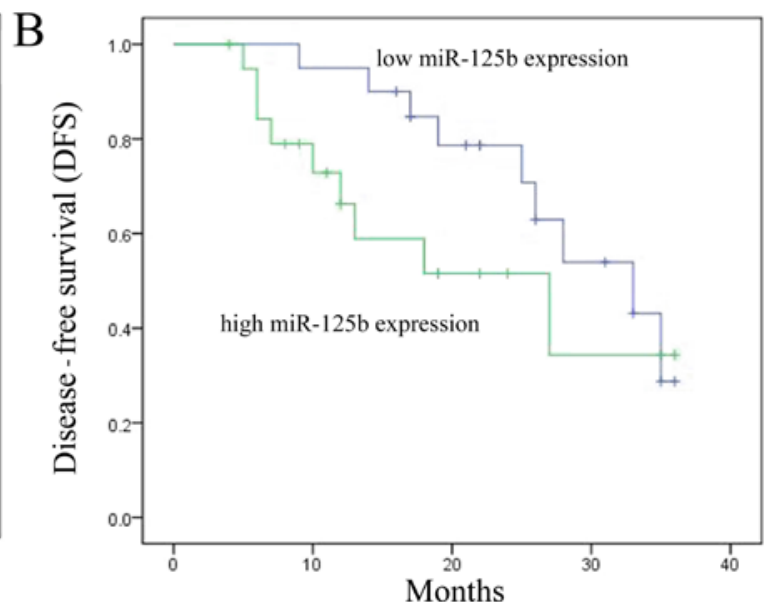

Figure 2. Association between miR-125b expression and OS and DFS rates. (A) OS and DFS (B) rates were recorded from a 3 -year follow-up of patients with non-small cell lung cancer. OS, overall survival; DFS, disease-free survival.

A

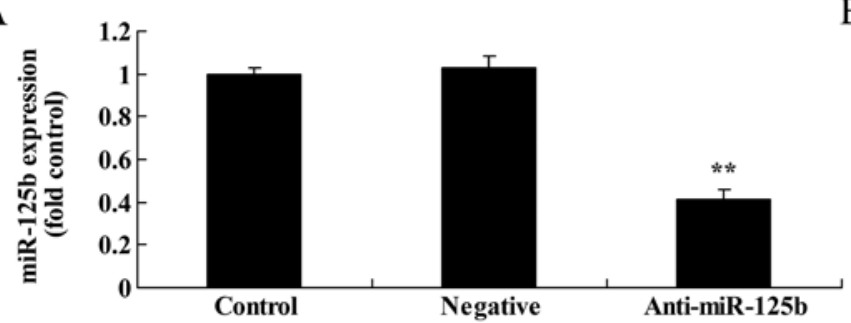

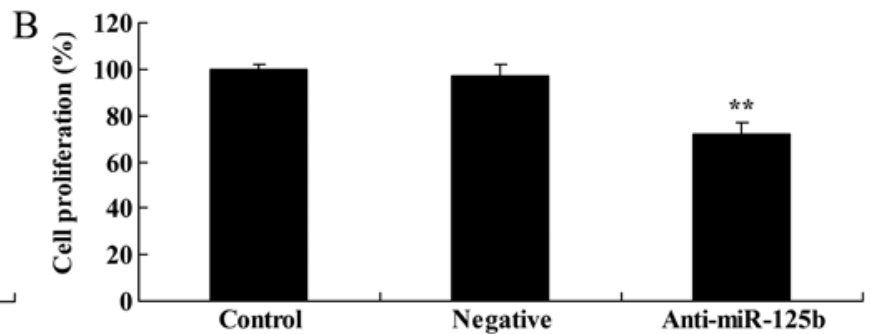

Figure 3. Downregulation of miR-125b inhibits the proliferation of A549 cells. Downregulation of miR-125b inhibited (A) miR-125b expression and (B) proliferation in A549 cells; ${ }^{* *} \mathrm{p}<0.01$ compared with the control group.

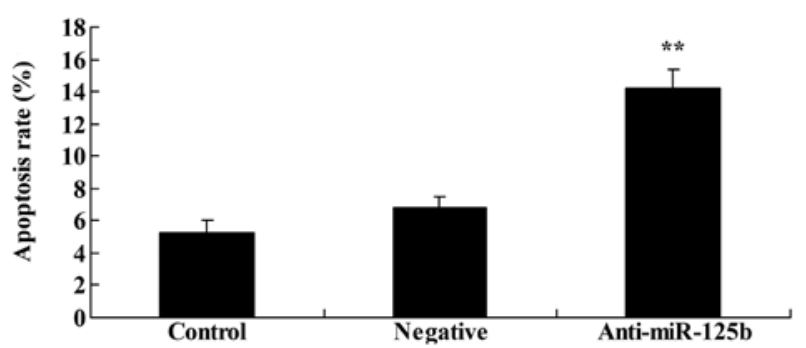

Figure 4. Downregulation of miR-125b induces apoptosis in A549 cells; ${ }^{* *} \mathrm{p}<0.01$ compared with the control group.

suppressed the expression of p-Akt (Fig. 5), p-GSK3 $\beta$ (Fig. 6), Wnt and $\beta$-catenin (Fig. 7) in A549 cells when compared with the negative control group.

Downregulation of $\mathrm{miR}-125 \mathrm{~b}$ increases caspase- 3 activity in A549 cells. To validate the effects of miR-125b on the apoptosis of A549 cells, the effects of miR-125b downregulation on the activity of caspase- 3 were assessed using a caspase- 3 activity ELISA kit. The results revealed that the downregulation of miR-125b significantly promoted caspase-3 activity in A549 cells when compared with the negative control group (Fig. 8).

Downregulation of miR-125b increases Bax protein expression in A549 cells. The effect of miR-125b on the apoptosis of A549 cells was also validated by assessing the protein expression of Bax following miR-125b downregulation by western blot analysis. As shown in Fig. 9, the downregulation of miR-125b significantly increased Bax expression in A549 cells when compared with the negative control group.

Downregulation of miR-125b combined with a PI3K inhibitor suppresses PI3K and p-Akt protein expression in A549 cells. Based on the aforementioned results, we explored the effect of a PI3K inhibitor on the growth of A549 cells after the downregulation of miR-125b. LY294002 was used as the PI3K inhibitor to suppress the PI3K/Akt pathway in A549 cells following miR-125b downregulation. As shown in Fig. 10, LY294002 markedly inhibited the expression of PI3K and p-Akt in A549 cells following the downregulation of miR$125 \mathrm{~b}$ at $48 \mathrm{~h}$, relative to a control group with only miR-125b downregulation.

Downregulation of miR-125b combined with a PI3K inhibitor enhances cell growth inhibition. We performed an MTT assay to assess the effects of miR-125b on the proliferation of A549 cells following PI3K inhibition. When compared with miR-125b downregulation alone, the PI3K inhibitor markedly inhibited the proliferation of A549 cells at $48 \mathrm{~h}$ following the downregulation of miR-125b (Fig. 11).

Downregulation of miR $-125 b$ combined with a PI3K inhibitor suppresses the protein expression of $p-G S K 3 \beta$, Wnt and $\beta$-catenin in A549 cells. To determine whether the 
A

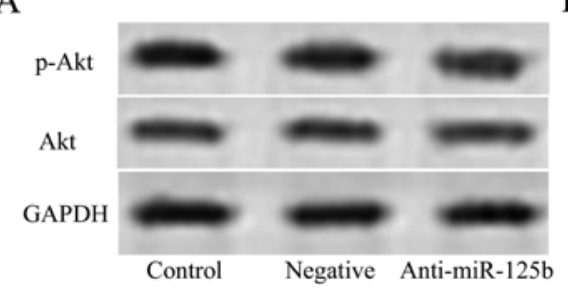

B

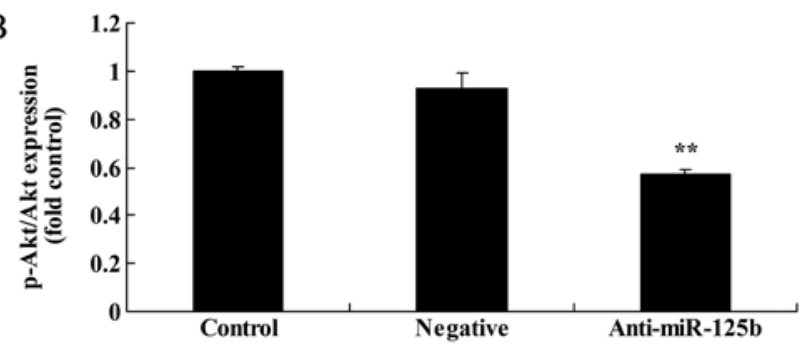

Figure 5. Downregulation of miR-125b suppresses the protein expression of p-Akt in A549 cells. Downregulation of miR-125b suppressed the protein expression of p-Akt, as indicated by (A) western blotting and (B) statistical analysis of p-Akt expression in A549 cells; ${ }^{* *}$ p $<0.01$ compared with the control group.

A

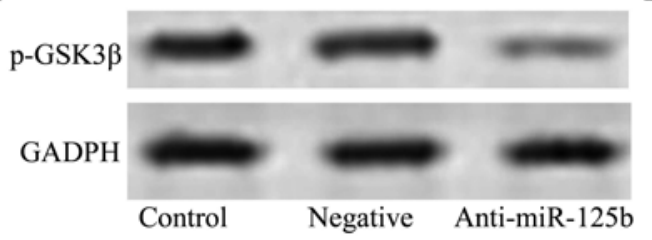

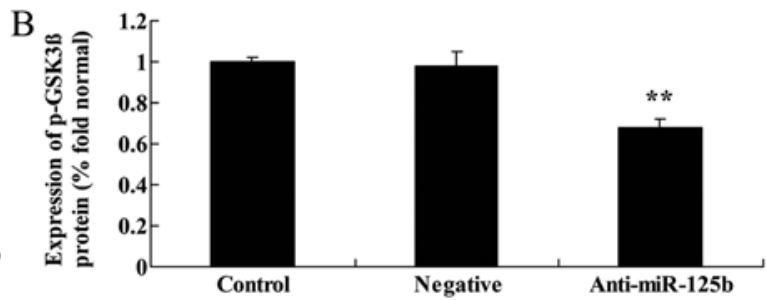

Figure 6. Downregulation of miR-125b increases Bax protein expression in A549 cells. Downregulation of miR-125b suppressed the protein expression of Bax, as indicated by (A) western blotting and (B) statistical analysis of Bax expression in A549 cells; *** $<0.01$ compared with the control group.

A

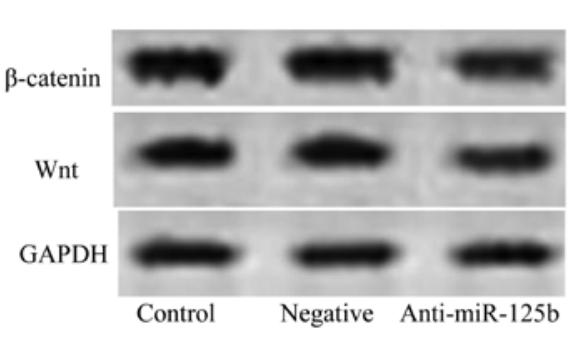

B

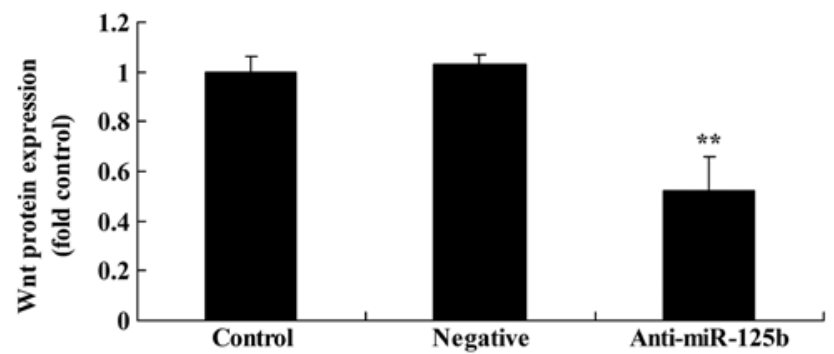

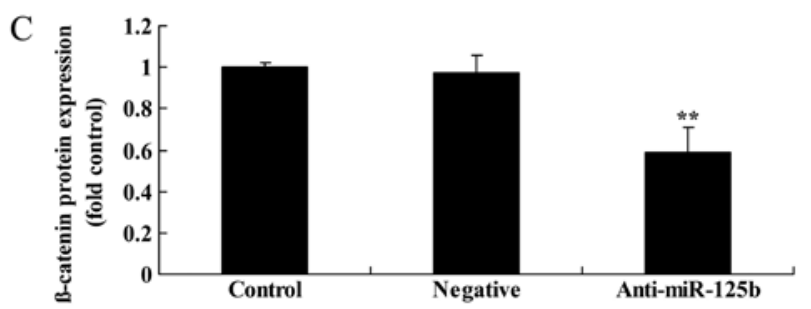

Figure 7. Downregulation of miR-125b suppresses the protein expression of Wnt and $\beta$-catenin in A549 cells. Downregulation of miR-125b suppressed the protein expression of Wnt and $\beta$-catenin, as indicated by (A) western blotting, (B) and statistical analysis of Wnt and (C) $\beta$-catenin expression in A549 cells; ${ }^{* *} \mathrm{p}<0.01$ compared with the control group.

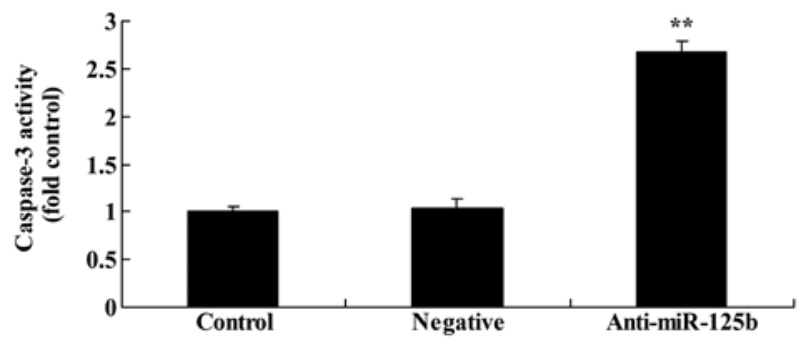

Figure 8. Downregulation of miR-125b increases caspase-3 activity in A549 cells; ${ }^{* *} \mathrm{p}<0.01$ compared with the control group.

downregulation of miR-125b combined with a PI3K inhibitor affected the expression of $\mathrm{p}-\mathrm{GSK} 3 \beta$, Wnt and $\beta$-catenin in A549 cells, western blot analysis was used to assess the expression of the proteins. Suppression of PI3K significantly decreased the expression levels of p-GSK3 $\beta$ (Fig. 12), Wnt and $\beta$-catenin (Fig. 13) in A549 cells following the downregulation of miR-125b at $48 \mathrm{~h}$, relative to a control group with only miR-125b downregulation.

Downregulation of miR-125b combined with a PI3K inhibitor promotes caspase-3 activity and Bax expression in A549 cells. To determine whether the downregulation of miR-125b combined with a PI3K inhibitor further promoted caspase-3 activity in A549 cells, caspase-3 activity in A549 cells was assessed using the caspase- 3 activity ELISA kit. The protein expression of Bax was also evaluated. The activation of 
A

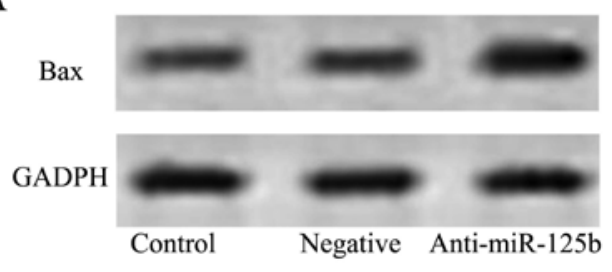

B

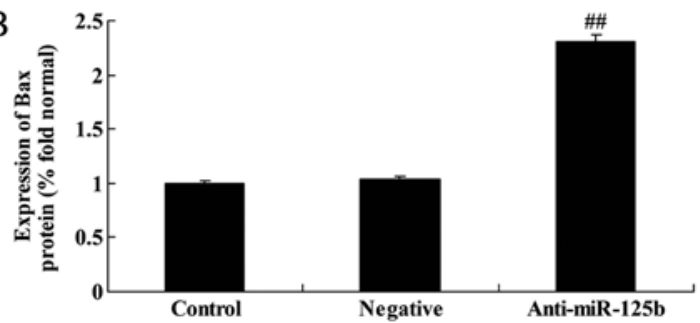

Figure 9. Downregulation of miR-125b increases Bax protein expression in A549 cells. Downregulation of miR-125b increased the protein expression of Bax, as indicated by (A) western blotting and (B) statistical analysis of Bax expression in A549 cells; ${ }^{\# \#} \mathrm{p}<0.01$ compared with the control group.
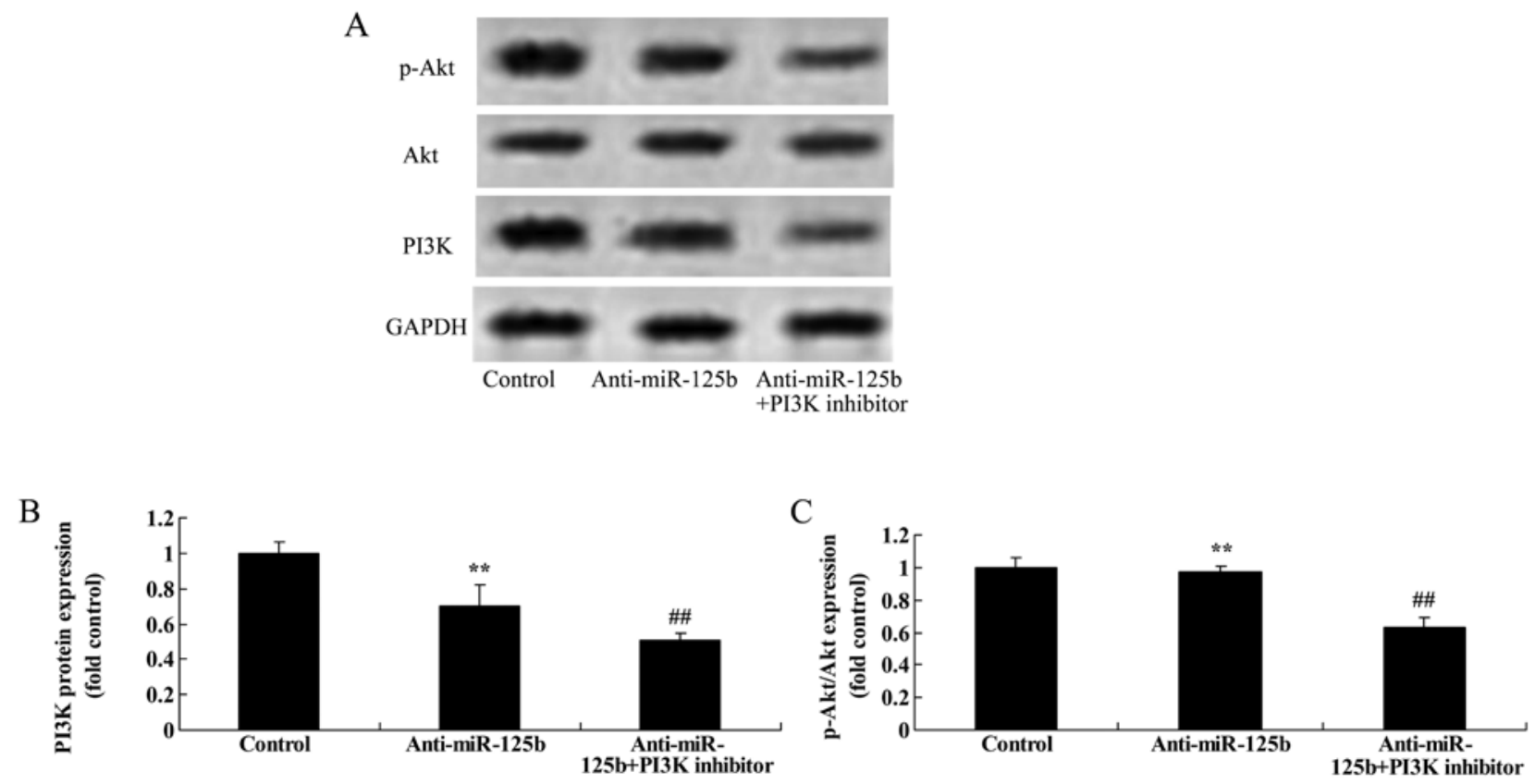

Figure 10. Downregulation of miR-125b combined with a PI3K inhibitor suppresses the protein expression of PI3K and p-Akt in A549 cells. Downregulation of miR-125b combined with a PI3K inhibitor suppressed PI3K and p-Akt protein expression, as indicated by (A) western blotting and statistical analysis of (B) PI3K and (C) p-Akt expression in A549 cells; ${ }^{* *} \mathrm{p}<0.01$ compared with the control group; ${ }^{\# \#} \mathrm{p}<0.01$ compared with the control group.

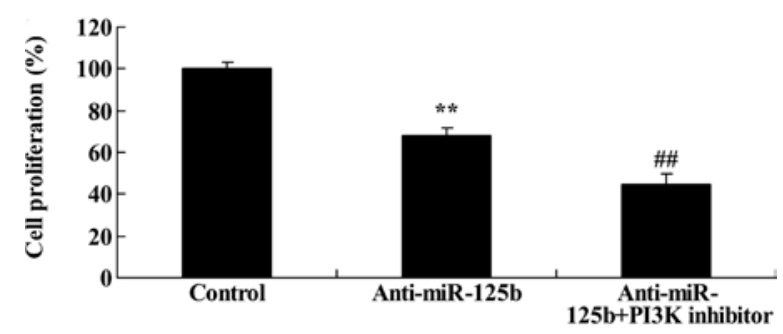

Figure 11. Downregulation of miR-125b combined with a PI3K inhibitor enhances cell growth inhibition; ${ }^{* *} \mathrm{p}<0.01$ compared with the control group; ${ }^{\# \#} \mathrm{p}<0.01$ compared with the control group.

caspase-3 and expression of Bax in A549 cells following downregulation of miR-125b was significantly increased by the PI3K inhibitor at $48 \mathrm{~h}$, relative to a control group with only miR-125b downregulation (Fig. 14).

\section{Discussion}

The treatment of cancer is a medical science challenge that to date has had limited success. Although tumor treatment has made progress in recent years, there is currently no fundamental method of curing cancer. Lung cancer is among the most common types of malignant tumors (17). A survey by the World Health Organization revealed that the morbidity rate of lung cancer in many countries and regions ranked the highest of all malignant tumors (18). This is particularly the case for China, where the morbidity rate of lung cancer is higher than that in America and other Western countries. NSCLC accounts for $\sim 70 \%$ of all lung cancer cases (19). Despite the use of surgical treatment for early-stage NSCLC, its 5-year survival rate remains relatively low at $\sim 30 \%$, while late-stage NSCLC has a one-year survival rate of $\sim 10 \%$ even after chemotherapy (20). To the best of our knowledge, the present study is the first to demonstrate that the downregulation of miR-125b could suppress the proliferation and promote the apoptosis of A549 cells.

The activated substrates of PI3K serve as second messengers on the plasmalemma and bind with the signaling proteins Akt and PDK1 via interactions with their $\mathrm{pH}$ structure domains (21). After Akt is recruited to the cytomembrane, it undergoes Ser124 and Thr450 phosphorylation, which promotes its catalytic activity (13). Akt can also be activated 
A

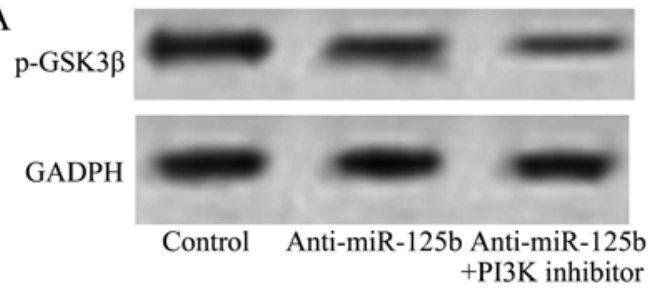

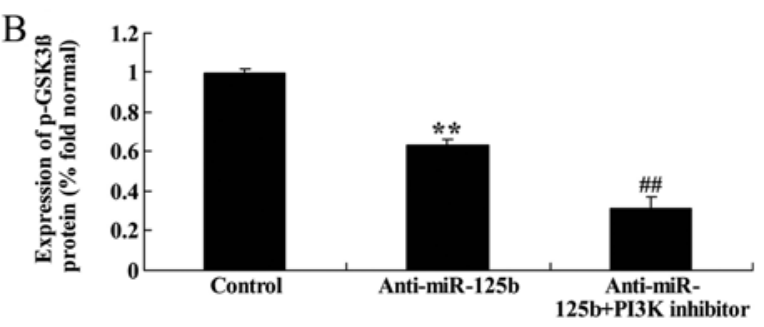

Figure 12. Downregulation of miR-125b combined with a PI3K inhibitor suppresses the protein expression of p-GSK3 $\beta$ in A549 cells. Downregulation of miR$125 \mathrm{~b}$ combined with a PI3K inhibitor suppressed p-GSK3 $\beta$ protein expression, as indicated by (A) western blotting and (B) statistical analysis of p-GSK3 $\beta$ expression in A549 cells; ${ }^{* *} \mathrm{p}<0.01$ compared with the control group; ${ }^{\# \#} \mathrm{p}<0.01$ compared with the control group.
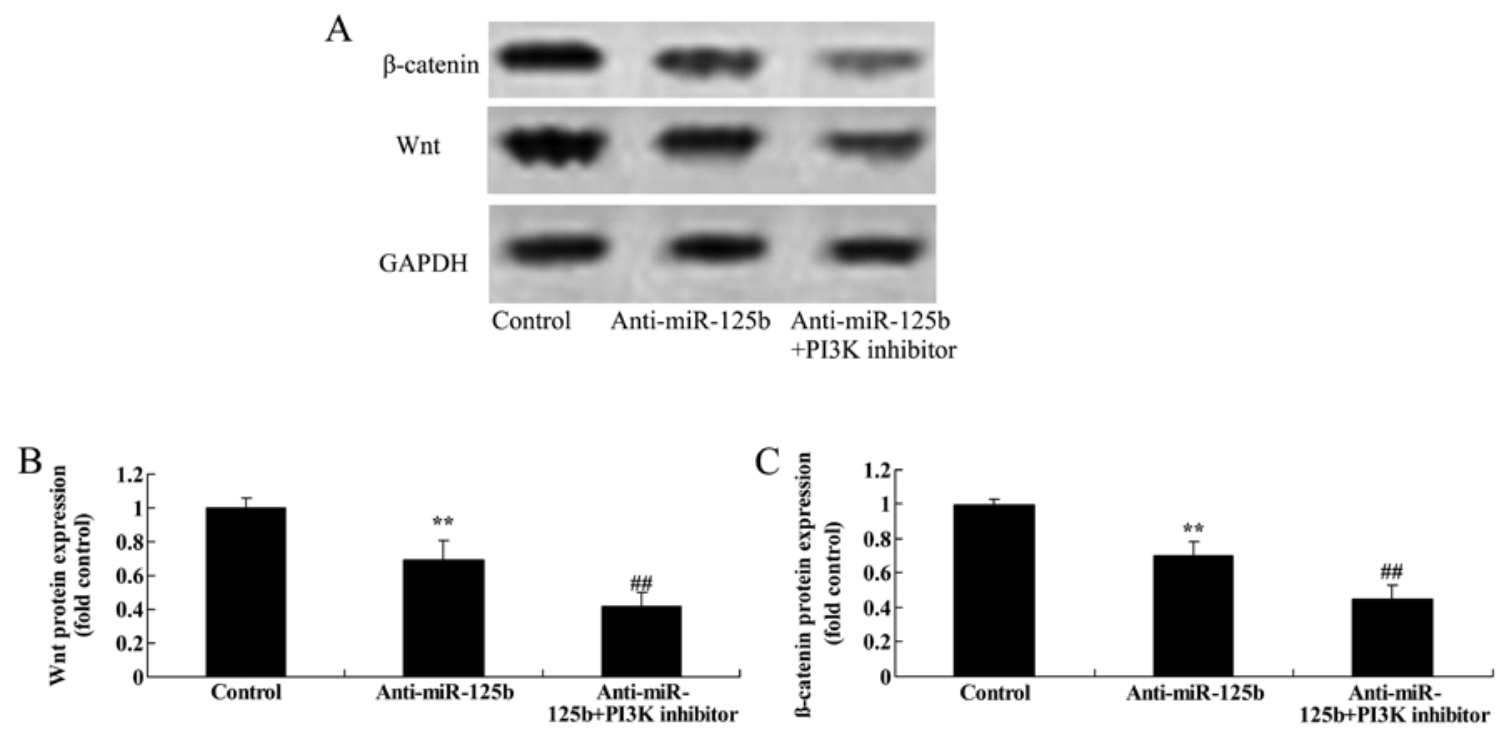

Figure 13. Downregulation of miR-125b combined with a PI3K inhibitor suppresses Wnt and $\beta$-catenin protein expression in A549 cells. Downregulation of miR-125b combined with a PI3K inhibitor suppressed Wnt and $\beta$-catenin protein expression, as indicated by (A) western blotting and statistical analysis of (B) Wnt and (C) $\beta$-catenin expression in A549 cells; * $\mathrm{p}<0.01$ compared with the control group; ${ }^{\# \#} \mathrm{p}<0.01$ compared with the control group.
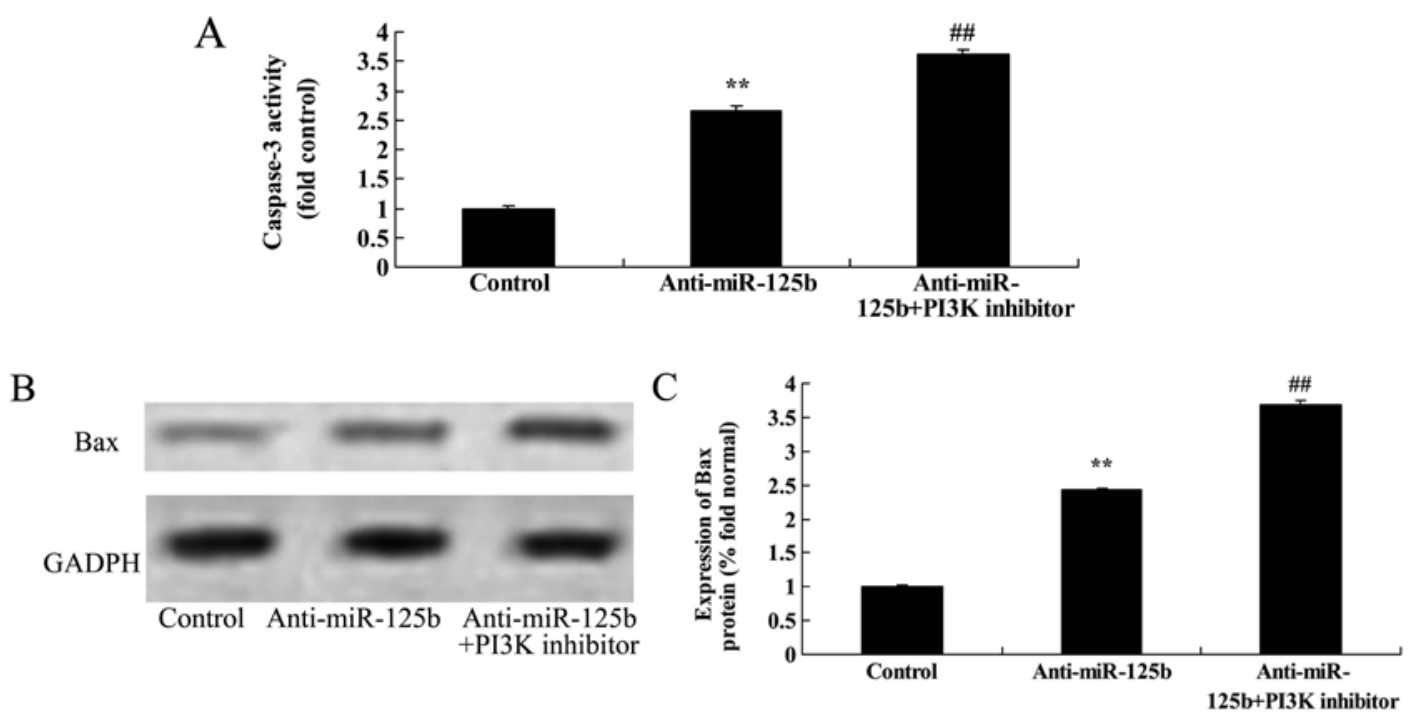

Figure 14. Downregulation of miR-125b combined with a PI3K inhibitor promotes caspase-3 activity and Bax expression in A549 cells. Downregulation of miR-125b combined with a PI3K inhibitor promoted (A) caspase-3 activity and (B and C) Bax expression in A549 cells; * $\mathrm{p}<0.01$ compared with the control group.

through phosphorylation of Ser473 mediated by PDK2 enzymes, such as integrin-linked kinase (11). The PI3K/Akt pathway induces tumor occurrence via multiple mechanisms: it downregulates the protein expression of p53 in the cell 
nucleus by promoting the nuclear translocation of Mdm2 tumor proteins (22); it promotes the abnormal proliferation of cancer cells at a transcriptional and translational level through excessive activation (23); and it can suppress the process of apoptosis through multiple mechanisms, including via inhibitory effects on the conformational changes of pre-apoptotic Bax, and via the phosphorylation of other apoptotic structures at the mitochondrial level (24). In the present study, we found that the downregulation of miR-125b significantly suppressed the protein expression of p-Akt in A549 cells. Furthermore, the present results revealed that a PI3K inhibitor suppressed the proliferation of A549 cells following the downregulation of miR-125b. Similarly, Shi et al reported that a PI3K inhibitor combined with a miR-125b inhibitor suppressed cell proliferation in glioma stem cell cancer through inactivation of the $\mathrm{Wnt} / \beta$-catenin signaling pathway (25). These data suggest that alterations in p-Akt expression could be involved in the regulatory effect of miR-125b downregulation on lung cancer progression.

Glycogen synthase kinase $3 \beta$ (GSK3 $\beta$ ) is a serine-threonine protein kinase. GSK $3 \beta$ can phosphorylate a variety of substrates, including metabolic and signaling proteins, cell structural proteins and transcription factors, and plays an important role in cell growth and development as well as tumor occurrence (26). GSK3 $\beta$ is an important kinase in the Wnt signaling pathway, where it acts as a key inhibitory factor that blocks Wnt signaling to inhibit tumor development (27). In the Wnt signaling pathway, GSK $3 \beta$ also serves as a key regulatory kinase that mediates the phosphorylation state of $\beta$-catenin in the $\beta$-catenin/Axin/APC complex (27). GSK3 $\beta$ is active in the absence of Wnt signaling, and catalyzes phosphate addition to four sites within the amino terminus of $\beta$-catenin, leading to its degradation and ultimately the inhibition of Wnt signal transduction (28). Our results revealed that the downregulation of miR-125b significantly decreased the protein expression of p-GSK3 $\beta$ in A549 cells.

$\beta$-catenin is not only a component of the cytomembrane epithelial cadherin $/ \beta$-catenin complex, but is also a critical molecule within the intracellular Wnt signal transduction pathway (29). $\beta$-catenin acts as an important link on the cytomembrane, where it aids to transduce downstream signals of the Wnt pathway into the nucleus (30). The $\beta$-catenin gene CTNNB1 is located on chromosome $3 \mathrm{p} 22$ and has a length of $23.2 \mathrm{~kb}$, which includes 16 exons. The third exon is regarded as a multi-functional factor. $\beta$-catenin is expressed on the cytomembrane of normal epithelial tissues (31). Its characteristics in the cytomembrane are shown in the figure. There are four ligands in the cytomembrane (32). Upon receipt of outside stimulation, signals are conducted to the cytoplasm from the cytomembrane, which involves phosphorylation of intracellular $\beta$-catenin. Phosphorylation of $\beta$-catenin enables its dissociation from the membrane and translocation to the nucleus, where it promotes gene transcription (33). Ectopic expression of $\beta$-catenin on the cytomembrane is generally rare, although a previous study of NSCLC showed that the levels of $\beta$-catenin in tumor tissues were significantly higher than those in normal lung tissues (32). The aberrant expression of $\beta$-catenin proteins has no obvious correlation with different tumor types or stages. However, the rate of aberrant expression of $\beta$-catenin has been reported to differ between
NSCLC tumors with different degrees of differentiation and different lymphatic metastasis statuses (31). A codon can be coded into the phosphorylated locus of GSK $3 \beta$. The mutation of the locus can cause abnormal accumulation of $\beta$-catenin, leading to cell proliferation and potentially tumorigenesis (30). The present study revealed that the downregulation of miR$125 \mathrm{~b}$ suppressed the protein expression of Wnt and $\beta$-catenin in A549 cells. In addition, PI3K inhibition combined with miR-125b downregulation suppressed the expression of Wnt and $\beta$-catenin in A549 cells to a greater extent than miR-125b downregulation alone. Zang et al reported that the E6 protein of human papilloma virus type 16 promoted cell growth through the downregulation of miR-125b and the activation of the Wnt/ $\beta$-catenin signaling pathway in esophageal cancer (34). Collectively these experiments indicate that PI3K/ Wnt/ $\beta$-catenin signaling may play a role in the suppression of NSCLC cell growth through the downregulation of miR-125b.

In summary, this study demonstrates for the first time that the downregulation of miR-125b can suppress the proliferation and promote the apoptosis of A549 cells, potentially through the suppression of PI3K/Wnt/ $\beta$-catenin expression. These findings may provide new insights into the mechanisms of miR-125 regarding its effects on PI3K/AKT and GSK3 $\beta / \mathrm{Wnt} / \beta$-catenin signaling and the development of NSCLC, and may aid in the development of potential diagnostic or therapeutic strategies for NSCLC.

\section{References}

1. Kelsey CR, Das S, Gu L, Dunphy FR III, Ready NE and Marks LB: phase 1 dose escalation study of accelerated radiation therapy with concurrent chemotherapy for locally advanced lung cancer. Int J Radiat Oncol Biol Phys 93: 997-1004, 2015.

2. Chiappori AA, Kolevska T, Spigel DR, Hager S, Rarick M Gadgeel S, Blais N, Von Pawel J, Hart L, Reck M, et al: A randomized phase II study of the telomerase inhibitor imetelstat as maintenance therapy for advanced non-small-cell lung cancer. Ann Oncol 26: 354-362, 2015.

3. Machtay M, Duan F, Siegel BA, Snyder BS, Gorelick JJ, Reddin JS, Munden R, Johnson DW, Wilf LH, DeNittis A, et al: Prediction of survival by $\left[{ }^{18} \mathrm{~F}\right]$ fluorodeoxyglucose positron emission tomography in patients with locally advanced nonsmall-cell lung cancer undergoing definitive chemoradiation therapy: Results of the ACRIN 6668/RTOG 0235 trial. J Clin Oncol 31: 3823-3830, 2013.

4. Wu C, Li F and Jiao SC: Prognostic factors for survival of patients with extensive stage small cell lung cancer - a retrospective single institution analysis. Asian Pac J Cancer Prev 13: 4959-4962, 2012.

5. Abhari K, Shekarforoush SS, Hosseinzadeh S, Nazifi S, Sajedianfard J and Eskandari MH: The effects of orally administered Bacillus coagulans and inulin on prevention and progression of rheumatoid arthritis in rats. Food Nutr Res 60: 30876, 2016.

6. Liao K, Li J and Wang Z: Dihydroartemisinin inhibits cell proliferation via AKT/GSK3 $\beta /$ cyclinD1 pathway and induces apoptosis in A549 lung cancer cells. Int J Clin Exp Pathol 7: 8684-8691, 2014.

7. Zhang Q, Zhu H, Xu X, Li L, Tan H and Cai X: Inactivated Sendai virus induces apoptosis and autophagy via the PI3K/Akt/ mTOR/p70S6K pathway in human non-small cell lung cancer cells. Biochem Biophys Res Commun 465: 64-70, 2015.

8. Li YC, He SM, He ZX, Li M, Yang Y, Pang JX, Zhang X, Chow K, Zhou Q, Duan W, et al: Plumbagin induces apoptotic and autophagic cell death through inhibition of the PI3K/Akt/ mTOR pathway in human non-small cell lung cancer cells. Cancer Lett 344: 239-259, 2014.

9. Saiki S, Sasazawa Y, Imamichi Y, Kawajiri S, Fujimaki T, Tanida I, Kobayashi H, Sato F, Sato S, Ishikawa K, et al: Caffeine induces apoptosis by enhancement of autophagy via PI3K/Akt/ mTOR/p70S6K inhibition. Autophagy 7: 176-187, 2011. 
10. Xiong F, Jiang M, Huang Z, Chen M, Chen K, Zhou J, Yin L, Tang Y, Wang M, Ye L, et al: A novel herbal formula induces cell cycle arrest and apoptosis in association with suppressing the PI3K/AKT pathway in human lung cancer A549 cells. Integr Cancer Ther 13: 152-160, 2014.

11. Trigka EA, Levidou G, Saetta AA, Chatziandreou I, Tomos P, Thalassinos N, Anastasiou N, Spartalis E, Kavantzas N, Patsouris E, et al: A detailed immunohistochemical analysis of the PI3K/AKT/mTOR pathway in lung cancer: Correlation with PIK3CA, AKT1, K-RAS or PTEN mutational status and clinicopathological features. Oncol Rep 30: 623-636, 2013.

12. Gadgeel SM and Wozniak A: Preclinical rationale for PI3K/Akt/ mTOR pathway inhibitors as therapy for epidermal growth factor receptor inhibitor-resistant non-small-cell lung cancer. Clin Lung Cancer 14: 322-332, 2013

13. Zhang C, Lan T, Hou J, Li J, Fang R, Yang Z, Zhang M, Liu J and Liu B: NOX4 promotes non-small cell lung cancer cell proliferation and metastasis through positive feedback regulation of PI3K/Akt signaling. Oncotarget 5: 4392-4405, 2014.

14. Yin H, Sun Y, Wang X, Park J, Zhang Y, Li M, Yin J, Liu Q and Wei M: Progress on the relationship between miR-125 family and tumorigenesis. Exp Cell Res 339: 252-260, 2015.

15. Duroux-Richard I, Pers YM, Fabre S, Ammari M, Baeten D, Cartron G, Touitou I, Jorgensen C and Apparailly F: Circulating miRNA-125b is a potential biomarker predicting response to rituximab in rheumatoid arthritis. Mediators Inflamm 2014: 342524, 2014.

16. Cui F, Li X, Zhu X, Huang L, Huang Y, Mao C, Yan Q, Zhu J, Zhao W and Shi H: MiR-125b inhibits tumor growth and promotes apoptosis of cervical cancer cells by targeting phosphoinositide 3-kinase catalytic subunit delta. Cell Physiol Biochem 30: 1310-1318, 2012.

17. Komaki R, Allen PK, Wei X, Blumenschein GR, Tang X, Lee JJ, Welsh JW, Wistuba II, Liu DD and Hong WK: Adding erlotinib to chemoradiation improves overall survival but not progressionfree survival in stage III non-small cell lung cancer. Int J Radiat Oncol Biol Phys 92: 317-324, 2015.

18. Edelman MJ, Tan MT, Fidler MJ, Sanborn RE, Otterson G, Sequist LV, Evans TL, Schneider BJ, Keresztes R, Rogers JS et al: Randomized, double-blind, placebo-controlled, multicenter phase II study of the efficacy and safety of apricoxib in combination with either docetaxel or pemetrexed in patients with biomarker-selected non-small-cell lung cancer. J Clin Oncol 33 189-194, 2015

19. Su S, Li T, Lu B, Wang X, Li J, Chen M, Lu Y, Bai Y, Hu Y, Ouyang $\mathrm{W}$, et al: Three-dimensional radiation therapy to the primary tumor with concurrent chemotherapy in patients with stage IV non-small cell lung cancer: Results of a multicenter phase 2 study from PPRA-RTOG, China. Int J Radiat Oncol Biol Phys 93: 769-777, 2015.

20. van Gool MH, Aukema TS, Schaake EE, Rijna H, Codrington HE, Valdés Olmos RA, Teertstra HJ, van Pel R, Burgers SA, van Tinteren $\mathrm{H}$, et al: ${ }^{18} \mathrm{~F}$-fluorodeoxyglucose positron emission tomography versus computed tomography in predicting histopathological response to epidermal growth factor receptortyrosine kinase inhibitor treatment in resectable non-small cell lung cancer. Ann Surg Oncol 21: 2831-2837, 2014.
21. Guo Y, Chang H, Li J, Xu XY, Shen L, Yu ZB and Liu WC: Thymosin alpha 1 suppresses proliferation and induces apoptosis in breast cancer cells through PTEN-mediated inhibition of PI3K/Akt/mTOR signaling pathway. Apoptosis 20: 1109-1121, 2015.

22. Paul A, Bishayee K, Ghosh S, Mukherjee A, Sikdar S, Chakraborty D, Boujedaini $\mathrm{N}$ and Khuda-Bukhsh AR: Chelidonine isolated from ethanolic extract of Chelidonium majus promotes apoptosis in HeLa cells through p38-p53 and PI3K/AKT signalling pathways. Zhong Xi Yi Jie He Xue Bao 10: 1025-1038, 2012.

23. Wang Y, Chen L, Huang G, He D, He J, Xu W, Zou C, Zong F, Li Y, Chen B, et al: Klotho sensitizes human lung cancer cell line to cisplatin via PI3k/Akt pathway. PLoS One 8: e57391, 2013.

24. Xu R, Shang C, Zhao J, Han Y, Liu J, Chen K and Shi W: Activation of M3 muscarinic receptor by acetylcholine promotes non-small cell lung cancer cell proliferation and invasion via EGFR/PI3K/AKT pathway. Tumour Biol 36: 4091-4100, 2015.

25. Shi L, Fei X, Wang Z and You Y: PI3K inhibitor combined with miR-125b inhibitor sensitize TMZ-induced anti-glioma stem cancer effects through inactivation of $\mathrm{Wnt} / \beta$-catenin signaling pathway. In Vitro Cell Dev Biol Anim 51: 1047-1055, 2015.

26. Carotenuto M, De Antonellis P, Liguori L, Benvenuto G, Magliulo D, Alonzi A, Turino C, Attanasio C, Damiani V,

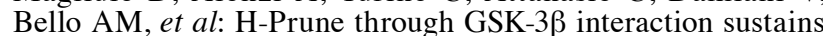
canonical WNT/ $\beta$-catenin signaling enhancing cancer progression in NSCLC. Oncotarget 5: 5736-5749, 2014.

27. Katoh M: WNT/PCP signaling pathway and human cancer (Review). Oncol Rep 14: 1583-1588, 2005.

28. Zheng H, Saito H, Masuda S, Yang X and Takano Y: Phosphorylated GSK3 $\beta-\operatorname{ser}^{9}$ and EGFR are good prognostic factors for lung carcinomas. Anticancer Res 27: 3561-3569, 2007.

29. Jiang HL, Jiang LM and Han WD: Wnt/ $\beta$-catenin signaling pathway in lung cancer stem cells is a potential target for the development of novel anticancer drugs. J BUON 20: 1094-1100, 2015.

30. Gao Y, Song C, Hui L, Li CY, Wang J, Tian Y, Han X, Chen Y, Tian DL, Qiu X, et al: Overexpression of RNF146 in non-small cell lung cancer enhances proliferation and invasion of tumors through the Wnt/ $\beta$-catenin signaling pathway. PLoS One 9: e85377, 2014

31. Li GH, Cui YS, Wu QY,Zhang XJ and Gao YF: Clinicopathologic significance of $\beta$-catenin and matrix metalloproteinase-2 expression in non-small cell lung cancer. Med Oncol 30: 437, 2013.

32. Chen CH, Chuang SM, Yang MF, Liao JW, Yu SL and Chen JJ: A novel function of YWHAZ/ $\beta$-catenin axis in promoting epithelial-mesenchymal transition and lung cancer metastasis. Mol Cancer Res 10: 1319-1331, 2012

33. Lee SB, Park YI, Dong MS and Gong YD: Identification of $2,3,6$-trisubstituted quinoxaline derivatives as a Wnt $2 / \beta$-catenin pathway inhibitor in non-small-cell lung cancer cell lines. Bioorg Med Chem Lett 20: 5900-5904, 2010.

34. Zang B, Huang G, Wang X and Zheng S: HPV-16 E6 promotes cell growth of esophageal cancer via downregulation of miR-125b and activation of Wnt $/ \beta$-catenin signaling pathway. Int J Clin Exp Pathol 8: 13687-13694, 2015. 